\title{
Perceptual scale expansion: an efficient angular coding strategy for locomotor space
}

\author{
Frank H. Durgin • Zhi Li
}

Published online: 19 May 2011

(C) Psychonomic Society, Inc. 2011

\begin{abstract}
Whereas most sensory information is coded on a logarithmic scale, linear expansion of a limited range may provide a more efficient coding for the angular variables important to precise motor control. In four experiments, we show that the perceived declination of gaze, like the perceived orientation of surfaces, is coded on a distorted scale. The distortion seems to arise from a nearly linear expansion of the angular range close to horizontal/straight ahead and is evident in explicit verbal and nonverbal measures (Experiments 1 and 2), as well as in implicit measures of perceived gaze direction (Experiment 4). The theory is advanced that this scale expansion (by a factor of about 1.5) may serve a functional goal of coding efficiency for angular perceptual variables. The scale expansion of perceived gaze declination is accompanied by a corresponding expansion of perceived optical slants in the same range (Experiments 3 and 4). These dual distortions can account for the explicit misperception of distance typically obtained by direct report and exocentric matching, while allowing for accurate spatial action to be understood as the result of calibration.
\end{abstract}

Keywords 3D perception: Space Perception - Visual perception $\cdot 3 \mathrm{D}$ perception: Depth and shape from X

A fundamental question in the study of space perception is why the apparent geometry of locomotor space is distorted. There are two well-documented biases in space perception that must be explained. First, slanted ground surfaces look much steeper to humans than they are (Kammann, 1967;

\section{F. H. Durgin $(\bowtie) \cdot$ Z. Li}

Swarthmore College,

500 College Avenue,

Swarthmore, PA 19081, USA

e-mail: fdurgin1@swarthmore.edu
Proffitt, Bhalla, Gossweiler, \& Midgett, 1995; Ross, 1974). Second, distances along the ground are underestimated (Foley, Ribeiro-Filho, \& da Silva, 2004; Gilinsky, 1951; Loomis, da Silva, Fujita, \& Fukusima, 1992). One attempt at an integrative theory is to suppose that compression of perceived space along the line of sight accounts for both biases (e.g., Ross, 2010), but such a distance-based account can only explain the overestimation of uphill slopes. Distance underestimation should make downhill slants viewed from the top seem shallower (i.e., more frontal to gaze; Ross, 1974), whereas downhill slopes actually appear steeper than they are (e.g., Li \& Durgin, 2009). Moreover, the haptic perception of slant is also exaggerated (Durgin, Li, \& Hajnal, 2010), even among people who are congenitally blind (Hajnal, Abdul-Malak, \& Durgin, in press). This suggests that biases in space perception are not simply due to visual error, but may have more general functional significance.

Some have argued that accurate motor performance demonstrates that these biases are epiphenomenal to perception for action (e.g., Proffitt et al., 1995). However, because action can be calibrated to distorted perception (Durgin, Hajnal, Li, Tonge, \& Stigliani, 2010; Harris, 1963), the accurate control of action depends not on perceptual accuracy but on the precision of the perceptual information made available for motor control and calibration (Durgin, 2009). Here, we propose that both the overestimation of slant and the underestimation of ground distance are the result of a coding strategy intended to enhance the precision of coded angular variables that are useful for action. The strategy, which we call scale expansion, consists of the perceptual system "magnifying" (by more densely coding) a portion of the ranges of two angular variables that are highly relevant for spatial actions such as locomotion. Our proposal is not that perceptual 
precision is actually increased by dense coding, but rather that existing precision in this part of the range might be better retained than in other parts of the range as the information moves upstream. (An analogy might be the observation that "cortical magnification" is even greater than retinal "magnification," but such cortical magnification occurs as a result of differences in the proportion of information retained, not by an increase in the amount of information.)

Perceptual systems code and transmit sensory information, transforming it through a bidirectionally interactive series of hierarchical stages into higher-level perceptual variables that are useful for the biological functions controlling both cognition and action. Due to limits in channel capacity, coding efficiency is important at all stages of processing (Barlow, 1990; Miller, 1956). Weber's law describes a logarithmic coding strategy in which perceptual precision remains relatively stable across a large input range. Logarithmic coding is efficient for those perceptual variables that have extended ranges, such as brightness and loudness. However, angular variables are bounded magnitudes. An alternative strategy for such variables is to densely code the portion of the range that is most relevant to the biological functions that use this angular information.

Gaze declination (the angular downward pitch of gaze) is an angular variable that is important for space perception, because it not only provides a direct measure of ground distance on level surfaces (Messing \& Durgin, 2005; Ooi, Wu, \& He, 2001; Sedgwick, 1986; Wallach \& O'Leary, 1982) but also, in combination with local optical slant (surface orientation relative to the line of gaze), can determine the local geographical slant of the ground (Gibson \& Cornsweet, 1952; Li \& Durgin, 2009; Sedgwick, 1986). When walking on level ground, there is a fixed mapping between the distance to a target on the ground (such as a rock) and the declination of gaze to that location. For locomotion, gaze declination rarely exceeds $60^{\circ}$ below horizontal during surface inspection, even for complex terrain (Marigold \& Patla, 2006), which means that the range of gaze declinations between $0^{\circ}$ and about $60^{\circ}$ is a candidate for perceptual scale expansion. That is, the actual range of gaze declinations could, in principle, be perceptually expanded by a factor of 1.5 in order to scale the range of $0^{\circ}-60^{\circ}$ to a perceptual range of $0^{\circ}-90^{\circ}$, which is the available range for angular coding between the categories of horizontal and vertical. In practice, the actual recoding would more likely produce an expansion of the lower part of the range (say, up to $50^{\circ}$ ), smoothly transitioning into compression of the range from $60^{\circ}$ to $90^{\circ}$ (see Durgin, Li, \& Hajnal, 2010, Figs. 2, and 6, where the range of $60^{\circ}-90^{\circ}$ is compressed into the perceptual range of $75^{\circ}$ to $90^{\circ}$ ).

For level ground to appear flat, however (rather than tilted downward), scale expansion of perceived gaze declination should be accompanied by a corresponding scale expansion of perceived slant relative to gaze (optical slant). In fact, we have recently shown that the perception of the geographical slants of near surfaces (within reach) are expanded in the range $\left(\sim 0^{\circ}-50^{\circ}\right)$ relevant for locomotion (Durgin, Li, \& Hajnal, 2010) and compressed in the upper range $\left(\sim 60^{\circ}-90^{\circ}\right)$. Note that geographical slant is defined relative to the vector of gravity (vertical) and the ground plane (horizontal), whereas optical slant is defined relative to the direction of gaze. For a geographical slant of zero (a horizontal surface), the optical slant (i.e., at the point of foveation) is numerically equivalent to the declination of gaze.

The dense coding of perceived gaze declination (or of perceived angular declination more generally) could provide two advantages for the control of action. First, the resulting scale affords more precise angular distance coding along the ground plane, by representing finer angular deviations between points along the ground. This kind of virtual amplification is valuable not at the sensory input stage (where it would amplify noise as well), but at the postsensory coding stage, for the sake of efficient transmission. For example, if one's neural coding scheme can represent 32 values along a dimension but distributes those values in proportion to likelihood of occurrence (e.g., devoting 24 of those values to one half of the range), this virtually expands the scale of that half of the range. Howe and Purves (2005) have made a related likelihoodof-occurrence analysis to try to account for biases in twodimensional angle perception (Dick \& Hochstein, 1989) based on natural image statistics.

Second, insofar as there is a corresponding scale expansion in the perception of optical slant, the two in combination will virtually amplify the perceived geographical slant of the ground when it departs from horizontal. A graphic depiction of our model is shown in Fig. 1, in which the expanded scaling of perceived gaze declination $\left(\gamma_{p}\right)$ is accompanied by a similar expanded scaling of perceived optical slant $\left(\beta_{\mathrm{p}}\right)$. The result of these two scale expansions would be to exaggerate perceived slant deviations from horizontal (making human actions more responsive to surface slant), but to reduce apparent egocentric distance along the ground.

There is a strong pretheoretical tendency to assume that proprioception, including such things as perceived gaze declination, should be unbiased, though there is lots of evidence to the contrary (e.g., Volcic, Kappers, \& Koenderink, 2007). In the case of gaze declination, it has been assumed that perceived gaze declination is coded accurately, on the basis of evidence of the accuracy of locomotor actions with respect to gaze declination (e.g., Ooi et al., 2001; see also Loomis \& Beall, 2004; Philbeck, Loomis, \& Beall, 1997). However, locomotor action is calibrated by perceptuo-motor 


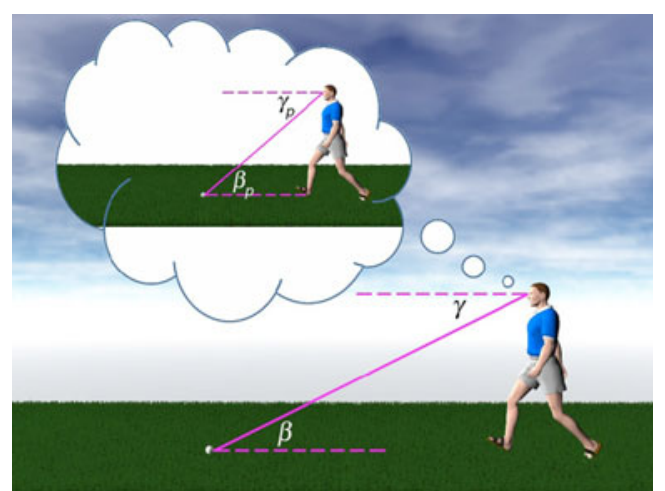

Fig. 1 Scale-expanded perceptual coding $\left(\gamma_{\mathrm{p}}\right.$ and $\left.\beta_{\mathrm{p}}\right)$ of both gaze declination $(\gamma)$ and optical slant $(\beta)$ amplifies departures of the ground plane from horizontal $\left(\beta_{\mathrm{p}}-\gamma_{\mathrm{p}}\right)$, while leaving level ground appearing flat but foreshortening distance along it. Expanded scaling of these angular variables may enhance coding of ground distance and surface slant for action control, while producing known biases in the perception of slant and distance

experience (Durgin et al., 2005; Rieser, Pick, Ashmead, \& Garing, 1995). This means that for measures of successful action to appear accurate, like walking to a previewed target or any other form of spatial updating (Loomis \& Philbeck, 2008), it is only required that perception be stable, rather than that it be unbiased.

A systematic distortion of perceived gaze direction (much like a prism-induced shift in perception) should not be evident as a bias in action if action has become calibrated to the distorted perception. Following prism adaptation, it is easy to remove prism glasses and observe systematic aftereffects. However, it is not possible to remove intrinsic perceptual distortions due to scale expansion. An attempt at direct measurement of perceptual experience is therefore called for. Indeed, there is preliminary evidence from direct and indirect measures that an exaggerated perception of gaze declination contributes to the exaggeration of perceived slope for downhill surfaces (Li \& Durgin, 2009), but the direct tests were conducted looking out of windows at distant targets and were not conducted with respect to near locomotor surfaces. Here, we measure perceived gaze declination toward a locomotor surface as an initial direct test of the scale expansion model.

\section{A note on the numeric estimation of orientation}

In Experiments 1, 3, and 4, we chose to use verbal numeric methods, as this is a fairly direct way of measuring perceptual experience in terms of angular variables. Unlike many forms of perceptual scaling, numeric estimates of orientation in degrees come with a built-in scale. That is, educated adults know that the range of orientations between horizontal and vertical constitutes $0^{\circ}-90^{\circ}$ and that a $45^{\circ}$ orientation represents the midpoint between horizontal and vertical. Thus, unlike with estimates of loudness, brightness, length, pain, and so forth, it is possible to assume that people share a common conceptual scale of orientation, with fixed numeric anchors.

Although all methods of measurement may be biased (e.g., by demand characteristics of experiments; Durgin et al., 2009), in a variety of studies we have found that numeric orientation estimates are remarkably robust as measures of the perceptual experience of slant (Durgin, Li, \& Hajnal, 2010; Hajnal et al., in press; Li \& Durgin, 2009, $2010,2011)$. For example, they have proven resistant to variations in the range of stimuli presented (Hajnal et al., in press) and are consistent with nonverbal probes, such as angle bisection (Durgin, Li, \& Hajnal, 2010), and even with implicit measures of slant, such as aspect ratio judgments for slanted configurations (Li \& Durgin, 2010).

In their study of perceived geographical slant, Durgin, Li, and Hajnal, (2010) showed that numeric estimates of slant made relative to vertical were largely indistinguishable from those made relative to horizontal, and that they corresponded well with nonverbal measures of a perceived slant that was judged to be midway between vertical and horizontal. That is, one group of people judged a surface of about $35^{\circ}$ (from horizontal) to be $45^{\circ}$ from vertical, another group judged it to be $45^{\circ}$ from horizontal, and nonverbal psychometric measurement in a third group indicated that a surface of about $34^{\circ}$ from horizontal appeared equidistant between vertical and horizontal. This shows that perceived slant is biased, but that verbal and nonverbal assessments are largely in agreement about the magnitude of the bias. Thus, numeric estimates of orientation seem to be fairly unbiased measures of a biased perceptual experience. In Experiment 2 of the present study, we collected angle bisection data to verify the generality of this conclusion regarding numeric angular estimation with respect to perceived gaze declination.

\section{Experiment 1: scale expansion in the perceived declination of gaze}

As a direct measure of explicitly perceived gaze declination, we had standing participants judge their gaze declinations toward a small ball placed at various locations along the ground. We used a grass field slanted by $6^{\circ}$ to discourage the use of cognitive trigonometric strategies based on perceived distance or on perceived optical slant.

Method

Participants A total of 20 undergraduates (10 female, 10 male) participated for payment. 
Stimulus The viewing target was a white golf ball $(4.3 \mathrm{~cm}$ in diameter) viewed while standing on a slanted field. Eight target locations, ranging from 2 to $9 \mathrm{~m}$ by $1-\mathrm{m}$ intervals, were used, while observers faced in both the uphill and downhill directions along the field. Figure 2 shows all eight of the target locations on the field. The range of gaze declinations tested was from $4^{\circ}$ to $45^{\circ}$, depending on participants' eye heights and the direction of the hill slope. In the uphill condition, the hill surface extended above the eye heights of the participants, and there was a large building just beyond the top of the hill. In the downhill condition, buildings and trees were visible in the far distance, but the sloped grass field extended well over $100 \mathrm{~m}$ in this direction, decreasing in slant to a shallow incline at the far end. Thus, no true horizon was visible in either direction.

The task We sought to have participants report the perceived pitch of their gaze (relative to a gravitationally defined horizontal framework) while looking directly at the target ball. Participants were briefly instructed that, on each trial, they were to look directly at the ball presented on the grass and to estimate the direction of their gaze, in degrees, relative to looking straight ahead (i.e., horizontal gaze). It was explained that looking straight ahead would be $0^{\circ}$, and looking down at one's feet would be $90^{\circ}$. In previous studies (e.g., Li \& Durgin, 2009), we found that people are able to report on proprioceptive angular variables such as perceived gaze declination and head orientation (e.g., with eyes closed). It is possible that some participants construed the task as judging the angular declination of the ball, but our instruction was to judge gaze direction.

Design On each trial, participants estimated their gaze declination toward a ball placed in front of them on a slanted grass field. Only one ball was visible at a time. Participants made verbal estimates of their direction of gaze while looking at the ball.

Numeric estimates were collected in each of two blocks of trials, with the first block considered as practice at the task. In each block, the eight distances were tested in random order, with the constraint that the initial trial was neither the closest $(2 \mathrm{~m})$ nor the farthest $(9 \mathrm{~m})$ distance. Males and females were separately randomly assigned to practice the task either looking up or down the hill. All participants then made eight analyzed estimates facing in the direction opposite from the one used during practice.

Procedure On each trial, one experimenter placed the ball on a concealed tee at the target location while the participant faced the other way. The participant was instructed to turn and make the judgment after the experimenter had left the field. A second experimenter gave these instructions and recorded verbal estimates. After making eight practice judgments, the participant was led on a circuitous path to the other end of the field to do the task from a new vantage point. After this, he or she was taken to an indoor location where a structured interview was conducted and standing eye height was measured.

Interview In the interview, we asked about three topics, concerning (1)the apparent slope of the field and beliefs about whether slopes look different than they are; (2) participants' beliefs about the design and purpose of the experiment, including the range of distances tested (estimated in feet); and (3)strategies used by participants when doing the task. Participants were asked at the end whether they golfed or skied, because these sports often lead to expertise in estimating distance and slope, respectively (Ross, 1974).

\section{Results}

The gaze estimation data of 3 participants ( 1 male) were eliminated from analysis because it became clear during the interview that they had misunderstood or disregarded the instructions (i.e., were trying to give estimates of geographical surface slant or of optical slant rather than of gaze declination). The measured eye heights of the remaining participants were used to compute their true angle of gaze to the eight ball locations, based on detailed measurement of the elevations of these locations. The gaze estimation data of 1 further participant were excluded because her

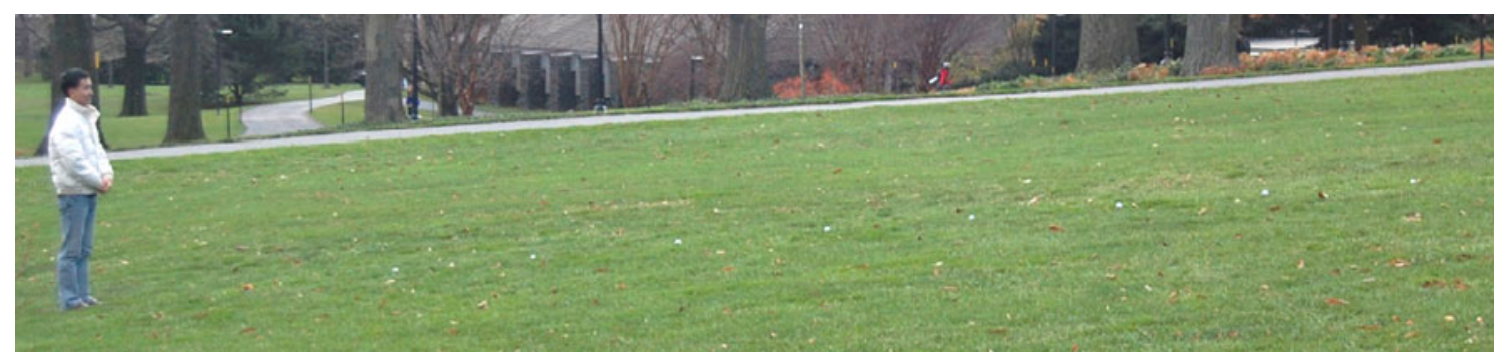

Fig. 2 All eight target locations in the uphill condition of Experiment 1. Only one target was visible at a time 
estimates were found to be uncorrelated with her actual gaze declinations $(r=-.14, p>.20)$, whereas these variables were highly reliably correlated for each of the other participants.

The complete data (128 estimates) and a best-fitting (dotted) line are shown in Fig. 3. The slope of this line indicates a gain of 1.53 , suggesting that there is indeed scale expansion of perceived gaze declination when observing a locomotor ground surface. It is worth noting that some of the between-subjects variability in the individual estimates is probably due to efforts at "consistency" (a principle mentioned by 10 participants during the interviews). For example, the four highest estimates in the downhill condition are due to 1 individual who gave a very high initial estimate, and then tried (as revealed later) to maintain "consistency" with her initial estimate. Her individual gain was 1.50 , but the intercept of her estimates was $30.9^{\circ}$ (which is strikingly similar to naïve estimates of the slope of the hill). When the slopes of individual fit lines were computed for each participant, the median gain was $1.46(M=1.45, S E=0.12)$. However, the median intercept was $9.6^{\circ}\left(M=9.1^{\circ}, S E=4.0^{\circ}\right)$, which suggests that participants overestimated the angular height of the horizontal in this experimental setting, which may be related to the fairly steep hill on which it took place.

The 1.5 gain cannot be explained by constant errors in perceived eye level (Matin \& Li, 1992; O'Shea \& Ross, 2007; Shebilske, 1986), which would produce a constant shift. However, to test for effects of surface slant on gaze estimates, separate smoothed fit lines were computed from the uphill and downhill estimates using local (quadratic) polynomial fits in the KernSmooth library (Wand \& Ripley, 2009) in $R$ ( $R$ Development Core Team, 2009), with a bandwidth of $8^{\circ}$. The two smoothed lines in Fig. 3 represent fits to the estimates facing up the slanted field (filled circles) and down the slanted field (open circles).

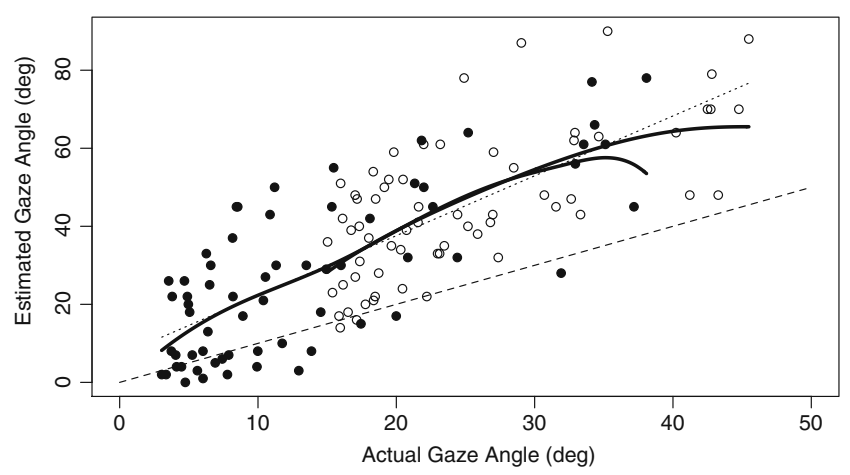

Fig. 3 Gaze declination estimates in Experiment 1 as a function of true declination. Filled circles are judgments of observers facing up the hill; empty circles represent judgments made while facing down the hill. Smoothed fit lines for the two conditions are shown, as is an overall linear fit (dotted line) with an intercept of $6.9^{\circ}$ and slope of 1.53
These smoothed lines do not seem to depart dramatically from the linear fit (dotted line) nor from each other, although they are consistent with a small shift in perceived eye level, such as has been reported when viewing slanted surfaces (O'Shea \& Ross, 2007).

In the structured interview following the main experiment, we determined that 8 participants were skiers or had otherwise acquired expert knowledge about errors in slope perception, and that 4 were golfers who might be expected to have expertise judging distance on grass. Estimates of the surface orientation of the field from memory given by the slope experts $\left(17^{\circ}\right)$ were reliably less than those of the naïve participants $\left(33^{\circ}\right), t(18)=2.51, p=.021$, but their gaze declination estimates still demonstrated a gain of 1.5. It is likely that expertise with verbal geographical slant estimation can lead to cognitive correction without altering the underlying perceptual coding (Granrud, 2009).

Misperception of gaze declination by a factor of 1.5 should cause egocentric distances along the ground to be underestimated by a factor of about 0.7 (as has been reported by Foley et al., 2004). When asked to estimate the farthest ball distance presented, nongolfers' mean verbal estimates from memory $(6.4 \mathrm{~m})$ were consistent with this prediction, and were reliably less than the actual distance of $9 \mathrm{~m}, t(15)=2.93, p=.01$. Golfers, in contrast, gave a mean estimate of the farthest distance of $10.3 \mathrm{~m}$. Nonetheless, their perceptual gain for gaze declination (1.7) did not differ reliably from 1.5. In addition to underestimating the farthest distances by a factor of 0.7 , nongolfers underestimated the nearest ball distance from memory, with a mean of $1.17 \mathrm{~m}$ ( $60 \%$ of the true $2 \mathrm{~m}$ ), whereas the average near estimate of the 4 golfers was $1.68 \mathrm{~m}(84 \%)$. Again, we suppose that the improved distance estimates of golfers are probably due to cognitive calibration based on explicit feedback available on golf courses, rather than to changes in their perceptual experience of distance.

\section{Discussion}

The exaggeration of perceived gaze declination is consistent with the idea that gaze declination is a powerful source of egocentric distance information (Ooi et al., 2001). Whereas walking without visual feedback to previewed targets is typically accurate for distances of up to $20 \mathrm{~m}$ (Loomis et al., 1992), such accurate action may result from the calibration of action based on internal forward models of the distorted perceptual experience implied by our data (Davidson \& Wolpert, 2005; Durgin, 2009). If action systems can code locomotor distances in terms of angular deviations of gaze, scale expansion in the coding of gaze declination will increase the precision of distance coding for action, even though the explicit estimation of linear extent is compressed. Here we have shown that judgments 
of the perceived declination of gaze are consistent with functional scale expansion (by a factor of 1.5) in the perceived declination of gaze. We have further observed that cognitive expertise regarding estimating geographical slant or estimating distance did not seem to affect estimates of gaze declination, even though it did affect estimates of geographical surface slant and of distance.

\section{Experiment 2: nonverbal confirmation of gaze declination error-A bisection task}

To confirm that our numeric estimation technique was not simply biasing, we conducted a second, nonverbal experiment with new observers in which we had them stand at different elevations and control the horizontal distance to a ball while attempting to position it at the gaze declination that appeared to them to bisect horizontal and vertical gaze. Based on a gain of about 1.5, we would expect the perceived $\left(45^{\circ}\right)$ bisection point to be about $30^{\circ}$ below horizontal, depending on the intercept. The outdoor context for the present experiment was a level ground surface, rather than a sloped one, and the ball was therefore suspended to discourage distance-based strategies.

\section{Method}

Participants A group of 16 undergraduate students (8 female, 8 male) participated.

Design Participants made adjustments at each of three eye heights: normal standing eye height, elevated by $0.93 \mathrm{~m}$, and elevated by $2.75 \mathrm{~m}$. The judgments were made with respect to a ball that was presented at an elevation of $0.59 \mathrm{~m}$ above the ground in order to discourage attempts at height/distance matching. For half of the participants, the ball distance was initially set to a position corresponding to a declination of about $30^{\circ}$. For the other half, it was always initially set to a distance corresponding to a declination of about $45^{\circ}$. Participants adjusted the ball location until the ball appeared to be at a gaze declination that bisected the angular distance between horizontal and vertical (i.e., subjectively $45^{\circ}$ below horizontal). It was anticipated that the apparent bisection point would be set closer to a physical declination of $30^{\circ}$ than to $45^{\circ}$. Trial order was randomized. A single trial was conducted at each eye height.

Apparatus Participants used a lever to control a small robotic vehicle that carried a white foam ball $(7.5 \mathrm{~cm}$ in diameter) on a support that elevated its center $59 \mathrm{~cm}$ above the ground. Viewer elevations other than normal eye height were obtained by having participants stand on the end of a set of bleachers at two different elevations. The ground was a flat grassy lawn facing a large building $30 \mathrm{~m}$ away.

Procedure Each participant drove the robotic vehicle forward or back until satisfied that the direction of their gaze to the suspended ball was $45^{\circ}$ below horizontal (i.e., the direction that bisected the angle between horizontal and vertical). A measurement was then taken of the ball position using a laser range finder, and the participant moved to a new position and turned his or her back while the next trial was readied. A brief interview was conducted at the end to ensure that participants had understood the instructions. Standing eye height was measured at the conclusion of the experiment.

\section{Results and discussion}

Each adjustment was converted to an actual angle of gaze declination based on trigonometry of the measured distance and eye height. The mean settings are plotted by elevation in Fig. 4. A repeated measures ANOVA found a reliable effect of viewing elevation, $F(2,28)=50.0, p<.0001$, but no effect of initial ball position (near or far), $F(1,14)<1$. The effect of elevation might be due to a number of factors, but was minor compared to the overall error. The overall mean setting corresponded to an actual gaze angle of $31^{\circ}\left(S E=2.7^{\circ}\right)$, which did not differ reliably from $30^{\circ}(t<1)$, but was reliably less than $45^{\circ}, t(15)=5.1, p=.0001$. This demonstrates, using a nonverbal task, that there is evidently a rather large overestimation of gaze declination consistent with a gain of about 1.5. For comparison, we estimated the perceived bisection point $\left(45^{\circ}\right)$ using regression lines fit to individual participants in Experiment 1. The mean was $25.7^{\circ}(S E=$ $2.7^{\circ}$ ), which may deviate from $30^{\circ}$ partly because of the large intercept found with the slanted ground surface. $\mathrm{Li}$ and

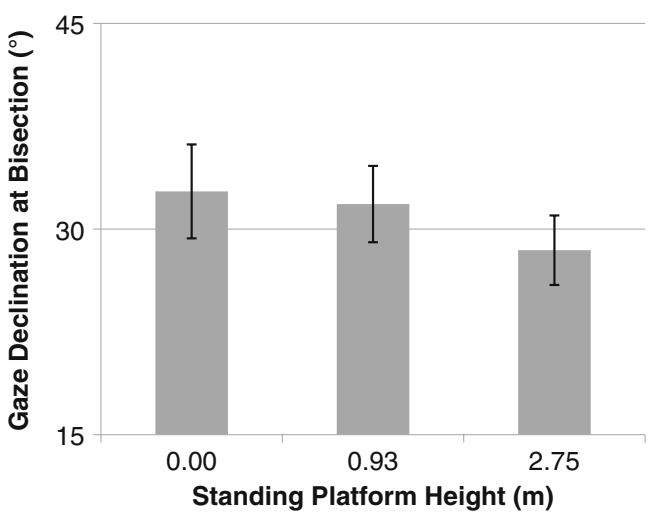

Fig. 4 Mean angular declination to target object when at apparent horizontal/vertical bisection point (perceived gaze declination of $45^{\circ}$ ), as a function of slanding platform height. Standard errors of the means are shown by whiskers 
Durgin (2009) recorded verbal estimates of gaze declination for objects viewed out of windows in the range from $8^{\circ}$ to $45^{\circ}$, and they computed a regression for verbal estimates of perceived gaze declination with a gain of $1.51(S E=0.18)$ and an intercept of $3.31^{\circ}\left(S E=5.2^{\circ}\right)$. Such values predict a perceived bisection point of $28^{\circ}$. On the whole, the measured bisection point in the present experiment corresponds fairly well with that predicted by prior verbal estimation data.

\section{Experiment 3: scale expansion in the perception of slant}

Li and Durgin (2009) have shown that perceived geographical slant for downhill surfaces can be modeled in terms of the integration of perceived gaze declination and perceived optical slant (using a fairly narrow range of optical slants). If frequent observation of horizontal ground planes serves to intercalibrate the perception of optical slant and the perception of gaze declination, we ought to expect to see evidence of optical slant overestimation that corresponds to that observed for gaze declination (as suggested by Fig. 1). We have recently reported evidence of exaggerations of geographical slope for surfaces in reach (Durgin, Li, \& Hajnal, 2010). Here we replicate the finding that surfaces with optical slants in the range relevant to locomotion show evidence of scale expansion with a gain of 1.5 with real objects. Although the present study confounds geographical and optical slant, it provides a real-world model for Experiment 4, in which an immersive simulated environment was used to rigorously decouple geographical and optical slant.

Although similar to Experiment 3 of Durgin, Li, and Hajnal, (2010), the present experiment differs in several respects: (1) For some observers, the surfaces were viewed at a distance of $2.5 \mathrm{~m}$ rather than within reaching distance. (2)
The surfaces used here were covered with three-dimensional (3-D) texture (gravel), rather than being completely flat surfaces. (3) The set of angles tested was limited to the range most relevant to locomotion (i.e., the same range used in Experiment 1). (4) A logarithmic range was used.

\section{Method}

Participants A total of 16 undergraduate students (8 female, 8 male) participated. Half were in the near viewing condition, and half were in the far viewing condition.

Design Participants were randomly assigned to either the near condition (viewing distance of $1 \mathrm{~m}$ ) or the far condition (viewing distance of $2.5 \mathrm{~m}$ ). Participants in both conditions made verbal estimates of the geographical surface orientation of real 3-D surfaces presented at eye level. With gaze forward, geographical slant and optical slant are geometrically the same in foveal vision. Eight surface orientations $\left(4.2^{\circ}, 6^{\circ}, 8.5^{\circ}, 12^{\circ}, 17^{\circ}, 24^{\circ}, 34^{\circ}\right.$, and $48^{\circ}$ from horizontal) were presented in random order in each of two blocks of trials.

Apparatus The surfaces used were 10 irregularly shaped gravel surfaces, each of which could be oriented in one of two ways on an adjustable metal slant platform, producing a total of 20 different surfaces to select from. The surfaces had been constructed by gluing gravel $(2-10 \mathrm{~mm}$ longest dimension) to foam core, the edges of which were finished with a locally cylindrical cord. The longest dimension of the surfaces ranged from 45 to $70 \mathrm{~cm}$, the short axes ranged from 35 to $46 \mathrm{~cm}$, and each board could be presented with either the longer or shorter axis sagittal to the viewer. Two of the surfaces are shown in Fig. 5.
Fig. 5 Example gravel boards (left) and mean estimates of slant (right). Standard errors of the means are shown

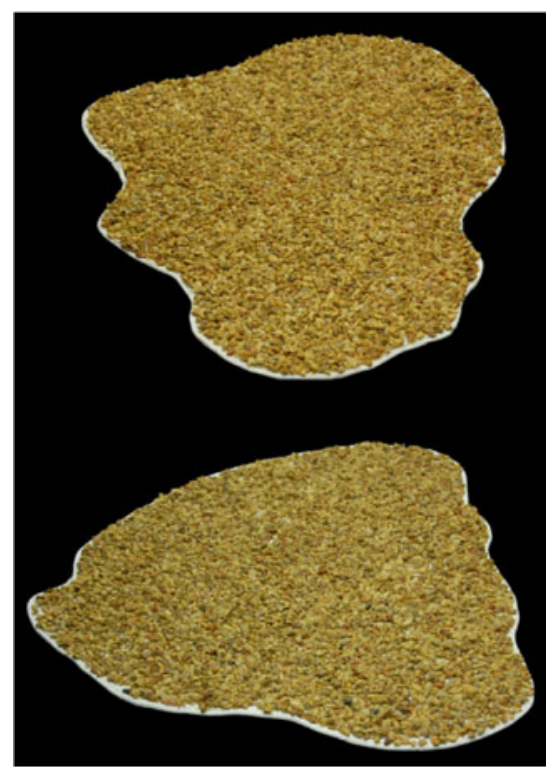


Procedure Each participant was seated with head stabilized in a chinrest and wore comfortable goggles that restricted the visible field to $100^{\circ} \times 50^{\circ}$ of visual angle. The surfaces were presented on a custom slant presentation device at eye level in front of a large hemisphere of black felt over $2 \mathrm{~m}$ in diameter (see Fig. 1 of Durgin, Li, \& Hajnal, 2010). Judgments of geographical slant were given verbally in degrees. (It was explained that surface slant was to be judged relative to horizontal, where a horizontal surface would be $0^{\circ}$ and a vertical surface $90^{\circ}$.) A new, randomly selected gravel surface was presented on each trial, with the long or short axis randomly selected to be sagittal to the observer.

\section{Results}

To test for effects of viewing distance, individual regression slopes were computed for each participant. The mean regression slope for verbal judgments in the near condition was 1.49. In the far condition, it was 1.54. These did not differ reliably, $t(15)=0.39, p>.20$, so the data are combined in Fig. 5. For the combined data of all 16 participants, the $95 \%$ confidence interval of regression slopes was from 1.39 to 1.65 . The linear fit of the mean slant estimates had a gain of $1.52\left(R^{2}=.999\right)$.

\section{Discussion}

Consistent with predictions of the scale expansion model, the present experiment demonstrates that perceived slant has a gain of 1.5 with respect to physical slant, which matches the gain found in Experiment 1 for gaze declination. Correspondence between scale expansion in perceived gaze declination and optical slant is to be expected, because the two variables can be calibrated to one another by means of observation of horizontal ground planes, as illustrated in Fig. 1. However, the present study did not distinguish between optical and geographical slant.

Durgin, Li, and Hajnal, (2010) found a similar gain for this range of geographical slants, even when they tested a larger range. That is, for geographical slants less than about $50^{\circ}$, they found evidence of scale expansion, whereas for geographical slants greater than $60^{\circ}$, they found evidence of scale compression (with fairly accurate performance at the categories of horizontal and vertical). Moreover, using simulations of large-scale surfaces but a smaller range of slants, Li and Durgin (2010) found a similar expanded scale for perceived slant, with a gain of about 1.5. This indicates that the present results are not simply an artifact of the range of slants tested or the size of the objects involved. Nonetheless, it remains to be seen in what sense optical slant, rather than merely geographical slant, shows scale expansion at the low end of the range.

\section{Experiment 4: scale expansion and the problem of optical slant}

Previously, it has been argued that downhill geographical slant can (empirically) be modeled by a combination of perceived gaze declination and optical slant (Li \& Durgin, 2009), consistent with the present theory. The optical slants used in that experiment were all between about $4^{\circ}$ and $36^{\circ}$. In other words, they were all fairly close to parallel to gaze, and all fell within the range of slants relevant to normal experience of the ground plane. To provide a more comprehensive contrast between optical slant and geographical slant in the present experiment, a larger range of optical slants was used to study uphill slant perception. This larger range was obtained by using a sophisticated immersive virtual environment to simulate small, irregularly shaped gravel surfaces that varied both in geographical slant and in the orientation of the line of gaze along which they were presented. Because geographical slant appears to be psychologically more accessible (Sedgwick \& Levy, 1985), we measured the perceived geographical slant of these surfaces, but we also measured the explicitly perceived declination of gaze to spheres presented in the same virtual environment. This allowed us to deduce the (implicit) perceived optical slant as a function of simulated optical slant (i.e., at the center of the surface), under the assumption that perceived geographical slant is derived from optical slant.

Sedgwick (e.g., 1983) has questioned the psychological reality of optical slant as a perceptual variable, proposing that geographical slant can be derived directly from the angular declinations of the surface horizon specified by perspective information on surfaces (i.e., the angular declination at the point where optical slants become $0^{\circ}$ ). In particular, Sedgwick and Levy (1985) found that the precision of matches with respect to geographical slant was greater than the precision of matches of optical slant. This difference in precision seems to contradict the idea that geographical slant is derived from optical slant. However, it remains possible, as noted by Sedgwick and Levy, that, even if observers do not normally attend to optical slant, it is still represented in the visual stream. Moreover, they found biases in matches of geographical slant toward matches in optical slant.

Geographical slant is probably of primary representational interest for the visual system. When varying the observation point for surfaces ranging from $0^{\circ}$ to $90^{\circ}$ in geographical slant, Durgin, Li, and Hajnal, (2010) reported that the ranges of scale expansion and scale compression defined by verbal report seemed to occur primarily with respect to geographical slant, not optical slant. This geographical slant constancy seems to pose a challenge to one of the ideas underlying our scale expansion model (see, 
e.g., Fig. 1) because the model proposes that scale expansion occurs with respect to optical slant. We sought in the present experiment to decouple geographical slant and optical slant to provide a more direct assessment of whether scale expansion effects could be linked to categories (like "parallel to gaze") that refer to optical slant.

If scale expansion occurs primarily with respect to geographical slant, as suggested by the results of Durgin, Li, and Hajnal, (2010), we should see evidence of it equally across all optical slants. Durgin, Li, and Hajnal found evidence of small effects of frontal optical slant, but their data primarily showed evidence of scale expansion with respect to geographical slant (horizontal). They did not test surfaces near to "parallel to gaze" that were not also nearly horizontal, though they did test horizontal surfaces that were not near to "parallel to gaze." Here, we included the converse case, in which nonhorizontal surfaces were presented that were viewed nearly parallel to gaze (see also Li \& Durgin, 2009).

\section{Method}

Participants A group of 30 undergraduate students (15 female, 15 male) participated in the main experiment on slant perception. Of these, 16 ( 9 female, 7 male) participated immediately afterward in a linked study of perceived gaze declination. One additional student, who failed a stereo test, was not included.

Design We used a sophisticated immersive virtual environment to present small gravel surfaces in the range from $18^{\circ}$ to $60^{\circ}$ of geographical slant. Participants made numeric estimates of geographical slant, instructed as in Experiment 3. The range of simulated slants was selected to avoid presenting geographical slants near the overlearned categorical orientations of horizontal and vertical. The slants were presented along each of the five declinations of gaze depicted in Fig. 6, from $-45^{\circ}$ (elevated gaze) to $45^{\circ}$ declined, producing a range of optical slants from $-27^{\circ}$ (when looking up at the underside of an $18^{\circ}$ surface) to $105^{\circ}$ (looking down at a $60^{\circ}$ surface). We also directly measured perceived direction of gaze (relative to horizontal gaze) in the same virtual environment, using balls as targets presented from $52.5^{\circ}$ to $-52.5^{\circ}$ of declination.

Apparatus The surfaces were simulated in an immersive virtual environment using an $\mathrm{nVis}$ head-mounted display $($ HMD) with a nominal resolution of $1,280 \times 1,024$. The display was pincushion-corrected and calibrated (Durgin \& Li, 2010; Kuhl, Thompson, \& Creem-Regehr, 2009) and updated at $60 \mathrm{~Hz}$ in stereo using professional rendering software (Virtools 4.1) in combination with an optical tracking system (Vicon) to monitor head position and

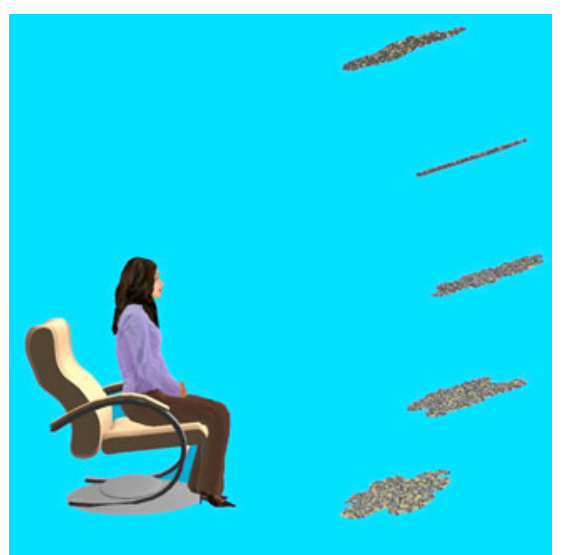

Fig. 6 A view from the side of simulated gravel surfaces at each of the five gaze declinations for the slant task of Experiment 4. Only one surface was visible at a time in the experiment. Note that the 3-D gravel textures were presented on both sides of the surfaces. The avatar depicts the participant's viewing location and was not represented in the experimental displays

orientation, which was corrected to each eye (at $60 \mathrm{~Hz}$ ) based on measured interpupillary distance (IPD), with a lag of less than $100 \mathrm{~ms}$.

The vertical field of view subtended $34^{\circ}$. Note that this means the horizon was certainly not visible when gaze was raised or declined more than $34^{\circ}$. To eliminate a conflicting depth cue represented by the edges of the image frame, a simulated aperture limited each eye's horizontal field of view to $33^{\circ}$, with $80 \%$ overlap, which simulated a $0.3-\mathrm{m}$ wide aperture, $0.5 \mathrm{~m}$ from the eyes for the average IPD of $62 \mathrm{~mm}$ (and a similar aperture for other IPDs). This simulated aperture was added because the physical aperture of our HMD screen was otherwise binocularly specified to be infinitely far away, which conflicts with the fact that it occludes near surfaces (Li \& Durgin, 2010, used the same technique). Observers sat in a comfortable chair with a low back that easily allowed the head to tilt forward or backward.

Virtual environment The surfaces were simulated at a viewing distance of $1.5 \mathrm{~m}$ (to the surface center), and were of irregular shape with a "diameter" of approximately $0.5 \mathrm{~m}$. They were planar, but textured with a randomized 3$\mathrm{D}$ object texture of rocks that protruded about $1.3 \mathrm{~cm}$ from the surface on both sides. The surrounding environment included a horizontal surface $10 \mathrm{~m}$ below eye level that extended to the horizon, thus visually specifying the horizontal. A distant texture of clouds was depicted in the upper sky.

Procedure After the task was explained and a participant's IPDs was entered, the participant was fitted with the HMD, and trials proceeded. There were 35 trials, representing the randomly ordered presentation of surfaces of $18^{\circ}, 25^{\circ}, 32^{\circ}$, $39^{\circ}, 46^{\circ}, 53^{\circ}$, and $60^{\circ}$ of geographical slant along each of 
five lines of sight (to the center of the surface) that were either elevated by $45^{\circ}$ or $22.5^{\circ}$ (i.e., negative gaze declination), lowered by $22.5^{\circ}$ or $45^{\circ}$, or straight ahead. Verbal estimates of geographical surface slant were collected on each trial. A stereo test was administered at the conclusion of the experiment using an $\mathrm{E}$ shape specified by a random dot stereogram. Participants had to indicate the direction (up, down, left, or right) that the $\mathrm{E}$ pointed.

After a short break, a subset of students also participated in a perceived gaze declination experiment in which a simulated white ball $(7.5 \mathrm{~cm}$ in diameter) was presented 1.5 $\mathrm{m}$ away along one of the 15 lines of sight from $52.5^{\circ}$ elevated (i.e., $-52.5^{\circ}$ ) to $52.5^{\circ}$, declined by increments of $7.5^{\circ}$. The background environment was the same as in the
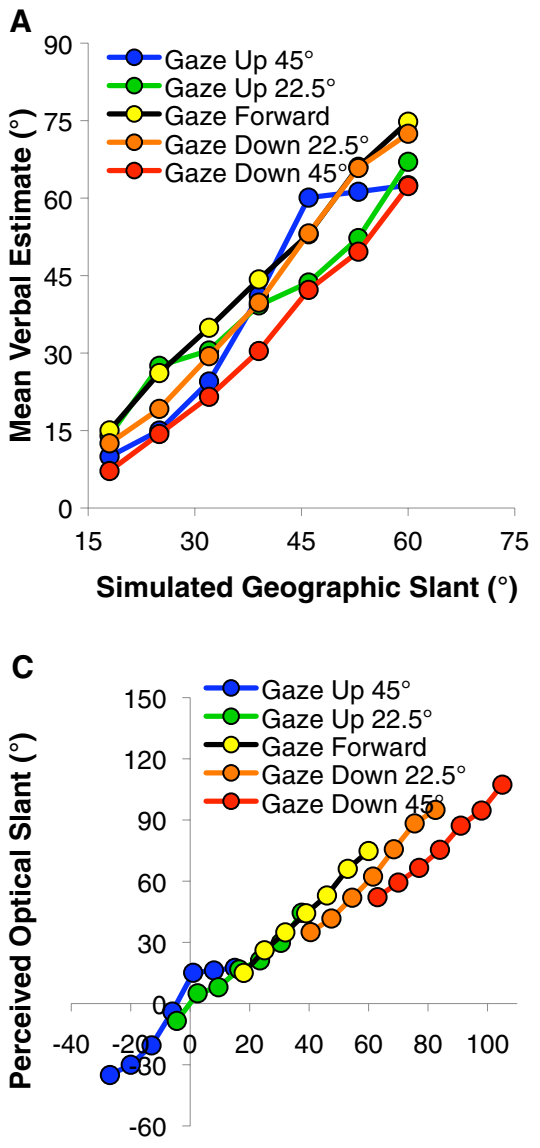

Simulated Optical Slant $\left({ }^{\circ}\right)$

Fig. 7 Results of Experiment 4. (a) Mean geographical slant estimates as a function of simulated geographical slant and direction of gaze. (b) Gaze declination estimation data from solitary white balls presented in the same virtual environment. Mean verbal estimates are plotted as a function of actual declination of gaze (negative values represent gaze elevation). Standard errors of the means are shown as whiskers. (c) Inferred perceived optical slant (estimated geographical slant - perceived gaze declination) as a function of simulated optical slant (simulated geographical slant - gaze declination), on the (false) main experiment. Trial order was random. Verbal estimates of gaze declination were recorded.

\section{Results}

The mean geographical slant estimates are plotted as a function of simulated geographical slant at each declination of gaze tested in Fig. 7a. We fit a line to each participant's data for each gaze direction. Geographical slant constancy should predict overlapping functions, but there are marked deviations from constancy in the data. In particular, when gaze was elevated by about $22.5^{\circ}$, the mean slope of the regression line (1.13) was highly reliably less than 1.5 , $t(29)=5.10, p<.0001$. None of the other gaze directions produced slopes that differed highly reliably from 1.5 (all of

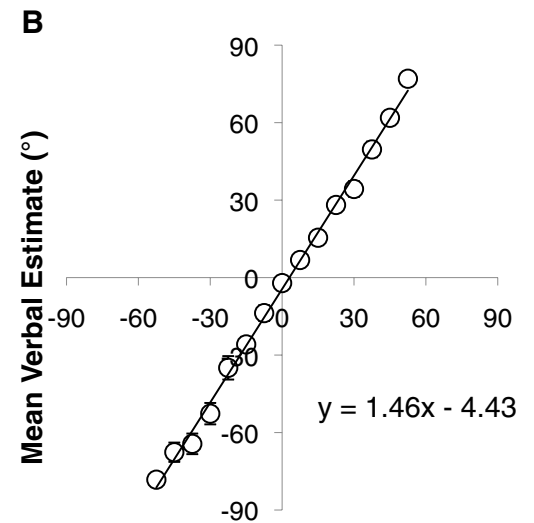

Actual Gaze Declination ( ${ }^{\circ}$ )

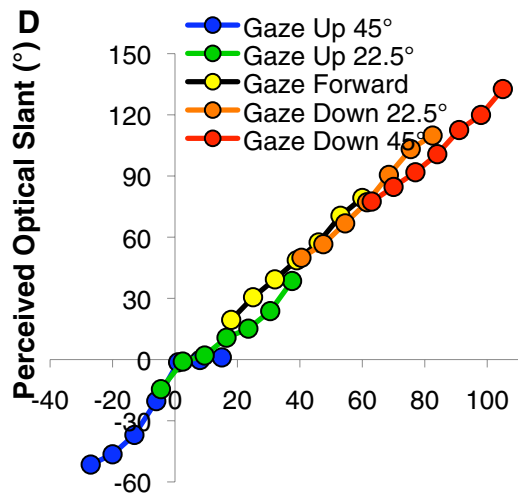

Simulated Optical Slant $\left(^{\circ}\right)$

assumption that gaze declination was perceived veridically. (d) Inferred perceived optical slant (estimated geographical slant perceived gaze declination) as a function of simulated optical slant (simulated geographical slant - gaze declination), based on direct estimates of geographical slant and of gaze declination. For simulated optical slants between $4^{\circ}$ and $50^{\circ}$, the slope is 1.52 . The plateau near $0^{\circ}$ indicates that when optical slant was shallow, the reports of geographical slant corresponded to later reports of perceived gaze declination 
these differed highly reliably from 1.0). However, when looking down at $45^{\circ}$, the slope (1.31) and overall estimates were systematically depressed (e.g., verbal estimates of geographical slant were marginally lower when gaze was so declined than when gaze was forward, $F(1,412)=3.28, p=$ $.0708)$, perhaps reflecting effects of the very high optical slants involved at this declination. Overall, the mean gain in geographical slant was only 1.36 (1.42, if we exclude the outlying condition).

The mean gaze declination estimates are plotted as a function of actual gaze direction in Fig. 7b. They show a mean gain of $1.46(S E=0.05)$, consistent with our prior experimental findings for estimates of perceived gaze declination, although the mean intercept is negative in this case $\left(M=-4.4^{\circ}, S E=1.1^{\circ}\right)$.

From estimates of geographical slant, we can try to infer perceived optical slant by either adding gaze declination to geographical slant estimates (Fig. 7c) or adding an estimate of perceived gaze declination to the geographical slant estimates (Fig. 7d). If gaze declination had been perceived accurately (Fig. 7c), the resulting inferred optical slant functions fail to form a coherent trend and exhibit an unexplained plateau near $15^{\circ}$ when optical slant is shallow. In contrast, Fig. $7 \mathrm{~d}$ shows deduced optical slant based on using a linear fit to the mean gaze declination data (Fig. 7b; $y=1.46 x-4.43, R^{2}=.996$ ); perceived gaze declination estimates derived from this function were computed for the five gaze orientations used in the slant experiment (on the assumption that gaze was toward the center of the surface).

Two features of Fig. 7d imply that this approach is better. First, the inferred optical slant estimates at the various gaze declinations now tend to form a single coherent function over most of the range. Second, the plateau formerly at $15^{\circ}$ is now clearly at $0^{\circ}$. An optical slant of $0^{\circ}$ represents a surface parallel to gaze. For the range of simulated optical slants between $0^{\circ}$ and $18^{\circ}$ (all viewed with gaze upward), the preponderance of mean optical slant estimates near $0^{\circ}$ in Fig. $7 \mathrm{~d}$ indicates that the geographical estimate given was the same as the perceived direction of gaze reported later. This plateau suggests that explicit measures of geographical slant in the present experiment, so interpreted, can serve as an implicit measure of perceived gaze declination. This implicit measure substantiates the explicit measures of gaze declination and also the claim that estimates of optical slant and of gaze declination can contribute to the perception of geographical slant.

Over the range of optical slants from $4^{\circ}$ to $50^{\circ}$ (which includes 14 distinct stimuli across four gaze declinations), the best-fitting gain was $1.52\left(R^{2}=.942\right)$, as in Experiment 3 . This is the range of optical slants most relevant to our theory. Participants tended to treat surface orientations with very shallow optical slants as essentially parallel to gaze, which is evidently what reduced the slope of the regression line for geographical slant judgments along the $22.5^{\circ}$-upward line of sight. The optical slant category of "frontal to gaze" does not seem to have influenced judgments as clearly. For example, the inferred perceived optical slant for a frontal surface is about $110^{\circ}$, rather than $90^{\circ}$. However, the depression of estimates when gaze was declined by $45^{\circ}$ suggests a possible influence of frontal effects (tending to reduce estimates of slant) competing with geographical slant constancy.

An overall linear fit to the mean optical slant data in Fig. 7d indicated a gain of 1.41 over the entire range of simulated optical slants from $-27^{\circ}$ to $105^{\circ}\left(R^{2}=.989\right)$. This overall gain is probably largely a consequence of the choice of geographical slants less than $60^{\circ}$, rather than a property of optical slant coding per se. Durgin, Li, and Hajnal, (2010) found a much shallower gain for geographical slants nearer to vertical, so if we had included such slants, we would probably have seen evidence of compression here, too. In other words, the main structure of our data may be determined by the trend toward geographical slant constancy (Fig. 7a), but there are residual patterns (evident in Fig. 7d) that implicate the optical slant categories of "nearly parallel to gaze" and "frontal to gaze." These patterns are also nascent in Fig. 7a (as plateaus just above "parallel to gaze," as steep repulsions just below "parallel to gaze," and as depressed geographical slant estimates for the viewing condition with optical slants that exceeded $90^{\circ}$ ). The optical slant category of "parallel to gaze" is of particular theoretical importance, because it defines the horizontal ground plane when gaze is forward.

\section{Discussion}

Overall, this experiment has qualified the theory inspired by a prior finding regarding downhill surface perception (Li \& Durgin, 2009). Here we have shown that the perceived geographical slants of uphill surfaces in the range of $18^{\circ}$ $60^{\circ}$ show scale expansion across a fairly wide range of gaze declinations and optical slants. This supports the idea that scale expansion of perceived slant may occur at postsensory stages, perhaps in the coding of geographical slant for transmission to other brain areas.

Equally important, however, is that trials in the present experiment for which the optical slant was near $0^{\circ}$ (parallel to gaze) provide implicit confirmation that the perceived declination of gaze is misperceived. That is, only when these data were interpreted with distorted estimates of perceived gaze direction did they become appropriately aligned with readily interpretable (near-zero) values of estimated optical slant. Although further work will be required to better characterize the interplay of optical slant and geographical slant in perception, the present experimental results suggest that both angular variables are psychologically important. 


\section{General discussion}

According to the scale expansion hypothesis, biases in space perception may result in part from perceptual coding strategies that seek to optimize coding precision prior to transmission to the rest of the brain. One major goal of visual processing is to compress relevant visual information into useful, transmittable packets. Inasmuch as gaze declination is typically limited to a relatively small range of angles (as during locomotion), the perception of gaze declination angles as larger than they are may reflect a coding scheme that makes them more distinct from one another than they otherwise would be. For the visual control of action, it is the precision of the perceptual representation available for action that matters most, because bias can be accommodated by adaptive calibration. We have thus suggested that there may be a functional explanation for the systematic perceptual underestimation of distance based on the expanded scale documented here in the coding of gaze declination. We have further suggested that this underestimation is therefore related to the systematic misperception of geographical slant as well, on the grounds that perceived gaze declination and perceived optical slant (with respect to the horizontal ground plane) should tend to share a common scale. In a series of four experiments, we have shown that the perceived declination of gaze exaggerates true gaze declination by a factor of about 1.5 , and we confirmed that a similar linear exaggeration of optical/geographical slant exists for the range of angles less than $60^{\circ}$ (see also Durgin, Li, \& Hajnal, 2010; Li \& Durgin, 2009, 2010). These effects cannot be explained as verbal bias, because they affect nonverbal angle bisection tasks as well.

So, how well does this scale expansion theory account for existing data on distance perception? Our observations regarding gaze declination are directly relevant to the perception of egocentric distance, and we have recently used a nonverbal matching task to verify that egocentric distances appear linearly compressed relative to frontal distances (Li, Phillips, \& Durgin, 2011). The compression is quantitatively consistent with the scale expansion of gaze declination. It is unlikely that distance compression is itself the cause of angular distortions in estimates of gaze declination, because we have previously observed these distortions in contexts in which distances were not easily estimated (Li \& Durgin, 2009). Similarly, in Experiment 4, we measured gaze declination to balls suspended in midair, for which distance compression seems an unlikely source of angular bias. Moreover, even golfers who show good calibration at estimating ground distance showed no advantage at estimating gaze declination in Experiment 1.

Loomis et al. (1992) developed an exocentric distance perception task based on the perceptual comparison of frontal extents with sagittal intervals along the ground extending away from the viewer in depth (see also $\mathrm{Wu}$, Ooi, \& He, 2004). Loomis and Philbeck (1999) pointed out that performance seemed to be related to optical slant, and $\mathrm{Wu}$ et al. noted that such a task can be construed as measuring an error in the perceived geographical slant of the ground (they modeled their data with an additive error). However, it can also be construed as measuring perceived optical slant, which according to our data (see also Li \& Durgin, 2010), appears to have a multiplicative bias. If an observer regards a stimulus configuration on a horizontal ground surface with gaze declined by $20^{\circ}$ (and thus an optical slant of $20^{\circ}$ ), but perceives his or her gaze to be declined by a much larger angle and has a corresponding misperception of optical slant (i.e., $30^{\circ}$ ), the observer should misperceive (underestimate) the length in depth by a predictable amount relative to the frontal interval. Conversely, given an actual incident gaze angle (optical slant) and an empirically measured length ratio that appeared equal to observers, we can infer the perceived optical slant and compute the ratio between the perceived and actual optical slants. A full derivation is provided in the Appendix.

In fact, for the 15 measured aspect ratios reported by Loomis et al. (1992, Experiment 1) for frontal intervals of 1-2 $\mathrm{m}$ presented at distances of 4-12 $\mathrm{m}$, the average computed ratio between the perceived and actual slants was $1.60 \pm 0.19(S D)$, which is quite close to the 1.5 gain factor for our angular scale expansion data from Experiments 1 and 2. For the 6 aspect ratios measured by Loomis and Philbeck (1999, binocular conditions), the average deduced ratio between perceived and actual gaze declinations was $1.56 \pm 0.14(S D)$. Thus, when measures of perceived aspect ratio between frontal ground extents and sagittal ground extents are interpreted as measures of perceived optical slant, they seem to reflect the same magnitude of angular scale expansion that we have measured directly both for perceived gaze declination and for perceived geographical and optical slant.

Our data show that gaze declination and optical/ geographical slant are both coded with an expanded scale at the shallow end of the range (near horizontal or parallel to gaze) that can account for perceptual exaggeration of surface deviations from horizontal by a factor of about 1.5. This is similar to the slant ratios found in the classic studies by Proffitt et al. (1995) for very steep hills (e.g., their $31^{\circ}$ hill was exaggerated in verbal reports by a factor of 1.6), but perceptual estimates for shallower hills (e.g., $5^{\circ}$ ) are proportionally much higher - on the order of four times their true slant. Because Proffitt et al. had viewers inspect hills with gaze forward, their studies have confounded the geographical slants of their hills with the viewing distances at which they were observed. That is, for a person of 
average eye height (e.g., $1.6 \mathrm{~m}$ ), a $31^{\circ}$ hill viewed with gaze forward could be observed at an optical distance of as little as $2.5 \mathrm{~m}$ (similar to the viewing distance we used in Experiment 3), depending on how close to the base of the hill the person stands. In contrast, a $5^{\circ}$ slope on which a person stands would be 18-19 $\mathrm{m}$ away at eye level. Bridgeman and Hoover (2008; see also Ross, 2010) have recently shown that farther portions of a constantly sloped path appear much steeper than nearer portions (in the range from 1 to $16 \mathrm{~m}$ along the ground).

Using large-scale virtual surfaces and both explicit (verbal) and implicit (L-shaped task) measures of optical slant, Li and Durgin (2010) found that perceived optical slant increases approximately linearly as a function of $\log$ distance, but that an expanded (1.5) gain for low slants is evident at each distance. In other words, the intercept rather than the slope of the function relating visually specified slant to perceived slant is increased by (logarithmic) increases in distance, but angular scale expansion is present at each distance. Li and Durgin (2010) proposed that the increasing exaggeration of low slants at far distances can be attributed to binocularly perceived depth compression over the relevant range of distances (see, e.g., Allison, Gillam, \& Vecellio, 2009).

Higashiyama (1992) reported that perceived visual angle is exaggerated in both the vertical and horizontal directions, but by more in the vertical than in the horizontal direction. Foley et al. (2004) also found evidence of perceptual exaggerations of effective visual angle, which they attributed to processes related to size constancy. Others have proposed that cognitive (McCready, 1986) or neural representations of perceived visual angle are affected by perceived distance (Murray, Boyaci, \& Kersten, 2006). These various reports suggest that the rescaling of angular variables may be a fairly general strategy in the human perceptual system. Elsewhere, we have argued that underconstancy in space perception may have important functional utility (Durgin, Ruff, \& Russell, in press). Here, we have provided a specific theory that attributes some forms of perceptual bias to functional goals relevant to information transmission for the control of action.

To our knowledge, our scale expansion theory is unique in proposing that the pervasive perceptual underestimation of distance measured by explicit estimation tasks may be the result of a functionally advantageous coding scheme rather than a mere failure of perception or of judgmental transformations (Cutting \& Vishton, 1995; but see Beusmans, 1998). Angular variables play a fundamental role in surface perception. Because action can be calibrated to a distorted perceptual representation (Durgin, Hajnal, et al., 2010; Harris, 1963), predictable and metrically precise perception is more important to the control of action than is metrical accuracy. The misperception of ground surface orientation is

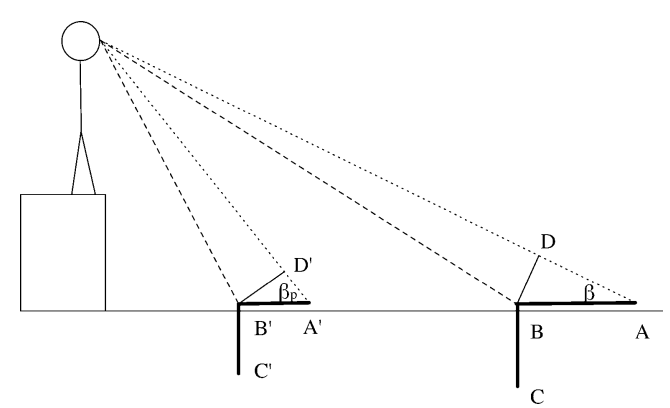

Fig. 8 Diagrammatic depiction of L-shape task for layout $A B C$, hypothesized to appear as being at a nearer location, such as $\mathrm{A}^{\prime} \mathrm{B}^{\prime} \mathrm{C}^{\prime}$. The underestimation of length $\mathrm{AB}$ relative to $\mathrm{BC}$ can be understood as resulting from the misperception of optical slant, $\beta$, as $\beta_{p}$

pervasive in humans; ramps feel steeper than they are (Hajnal et al., in press). We have proposed that coding advantages useful for immediate locomotor action may be obtained by the expanded scaling of angular variables for the ranges most frequently encountered. This expanded scaling comes at the cost of the confusability of steeper orientations, as demonstrated by the vertical tendency (Durgin, Li, \& Hajnal, 2010).

Here we have shown that both perceived slant and perceived gaze declination are overestimated during the normal perception of near and far surfaces. In locomotor space, these dual angular scale expansions can largely account for known errors in the perception of ground extent as well as surface orientation, while providing a functional explanation for both. We suggest that perceptual scale expansion is an advantageous coding strategy that increases the coding density of functionally significant angular information so that actions guided by that information may have access to a more fine-grained representation.

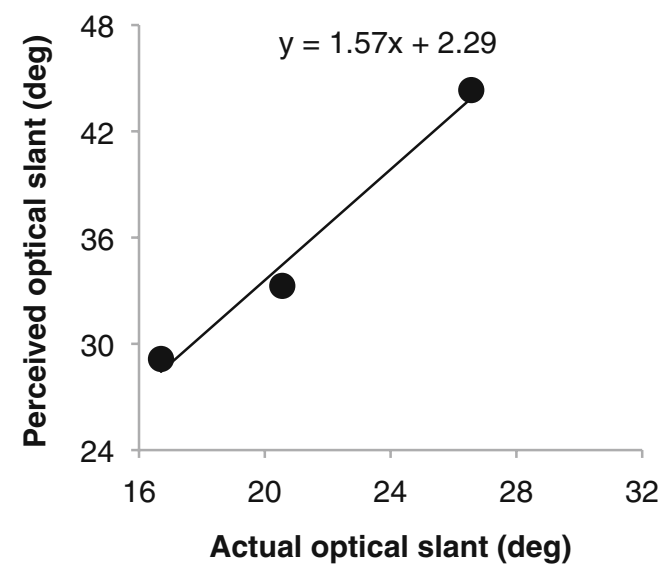

Fig. 9 Extent anisotropy data for elevated observers (Loomis \& Philbeck, 1999) expressed as perceived optical slant as a function of true optical slant. The linear fit to the data indicates a gain of about 1.57 
Author note This research was supported by Award R15EY021026-01 from the National Eye Institute. The content is solely the responsibility of the authors and does not necessarily represent the official views of the National Eye Institute or the National Institutes of Health. This work was also supported by Hans Wallach fellowship funds and by a Swarthmore College Faculty Research Grant. Anthony Stigliani and John Phillips assisted with collection of data. We are grateful to Hal Sedgwick, Jack Loomis, and two anonymous reviewers for their comments and suggestions on earlier drafts.

\section{Appendix}

Here we show how we derived an optical slant ratio from the aspect ratio data of Loomis et al. (1992) and Loomis and Philbeck (1999). (See Li \& Durgin, 2010, for a general formulation, and Ooi, Wu, \& He, 2001, for an alternative derivation assuming an additive error in ground slant.) In these studies, an L-shape is constructed on a level surface such that one bar of the L lies in the sagittal plane and one lies in a frontal plane on the ground. Observers either adjust the sagittal length to make it appear equal to the frontal length or report the apparent ratio between the observed lengths. Normally, the sagittal extent is set too long or its length ratio is underestimated relative to the frontal length.

To explain how we quantified this as an error in optical slant perception, consider Fig. 8. Points A, B, and C, are specified on a ground plane forming two segments at right angles to one another. $\mathrm{AB}$ is a sagittal extent; $\mathrm{BC}$ is frontal to the viewer, along the ground. $\mathrm{BD}$ is a frontal projection of $\mathrm{AB}$, perpendicular to the line of sight to $\mathrm{A}$ in the same plane as $\mathrm{BC}[\mathrm{AB}=\mathrm{BD} / \sin (\beta)]$. If the task is to judge the ratio $(\mathrm{R})$ between $\mathrm{AB}$ and $\mathrm{BC}$, the correct $\mathrm{R}=\mathrm{BD} /[\mathrm{BC} * \sin (\beta)]$. If the layout $\mathrm{ABC}$ is perceived as being at a near location $\mathrm{A}^{\prime} \mathrm{B}^{\prime} \mathrm{C}^{\prime}$, with $\beta$ being misperceived as $\beta_{\mathrm{p}}$, however, the perceived aspect ratio $\mathrm{R}_{\mathrm{p}}=\mathrm{B}^{\prime} \mathrm{D}^{\prime} /\left[\mathrm{B}^{\prime} \mathrm{C}^{\prime} * \sin \left(\beta_{\mathrm{p}}\right)\right]$. Because $\mathrm{BD}$ and $\mathrm{BC}$ are both frontal extents, we assume that $\mathrm{B}^{\prime} \mathrm{D}^{\prime} / \mathrm{B}^{\prime} \mathrm{C}^{\prime}=\mathrm{BD} / \mathrm{BC}$. Thus, we can deduce the slant ratio of $\beta$ (i.e., $\beta_{\mathrm{p}} / \beta$ ) by calculating $\beta_{\mathrm{p}}=\arcsin \left[\sin (\beta)^{*} \mathrm{R} / \mathrm{R}_{\mathrm{p}}\right]$. Note that the slant ratio is not the same as the slant gain unless the intercept can be assumed to be zero. For most aspect ratio tasks, optical slant is confounded with viewing distance. However, Loomis and Philbeck (1999) elevated their observers to maintain the same set of optical slants at farther viewing distances. When their viewers were elevated to an eye height of $5.85 \mathrm{~m}$ and made $\mathrm{L}$ ratio judgments along the ground, the function relating perceived optical slant to actual optical slant provided an excellent fit to our scale expansion model, as shown in Fig. 9.

\section{References}

Allison, R. S., Gillam, B. J., \& Vecellio, E. (2009). Binocular depth discrimination and estimation beyond interaction space. Journal of Vision, 10(1), 1-14. doi:10.1167/9.1.10
Barlow, H. B. (1990). A theory about the functional role and synaptic mechanism of visual after-effects. In C. Blakemore (Ed.), Vision: Coding and efficiency (pp. 363-375). Cambridge: Cambridge University Press.

Beusmans, J. M. H. (1998). Optic flow and the metric of the visual ground plane. Vision Research, 38, 1153-1170.

Bridgeman, B., \& Hoover, M. (2008). Processing spatial layout by perception and sensorimotor interaction. The Quarterly Journal of Experimental Psychology, 61, 851-859.

Cutting, J. E., \& Vishton, P. M. (1995). Perceiving layout and knowing distances: The integration, relative potency, and contextual use of different information about depth. In W. Epstein \& S. Rogers (Eds.), Handbook of perception and cognition: Vol. 5. Perception of space and motion (pp. 69-117). San Diego: Academic Press.

Davidson, P. R., \& Wolpert, D. M. (2005). Widespread access to predictive models in the motor system: A short review. Journal of Neural Engineering, 2, S313-S319.

Dick, M., \& Hochstein, S. (1989). Visual orientation estimation. Perception \& Psychophysics, 46, 227-234.

Durgin, F. H. (2009). When walking makes perception better. Current Directions in Psychological Science, 18, 43-47.

Durgin, F. H., Baird, J. A., Greenburg, M., Russell, R., Shaughnessy, K., \& Waymouth, S. (2009). Who is being deceived? The experimental demands of wearing a backpack. Psychonomic Bulletin \& Review, 16, 964-969.

Durgin, F. H., Hajnal, A., Li, Z., Tonge, N., \& Stigliani, A. (2010). Palm boards are not action measures: An alternative to the twosystems theory of geographical slant perception. Acta Psychologica, 134, 182-197.

Durgin, F. H., \& Li, Z. (2010). Controlled interaction: Strategies for using virtual reality to study perception. Behavior Research Methods, 42, 414-420.

Durgin, F. H., Li, Z., \& Hajnal, A. (2010). Slant perception in near space is categorically biased: Evidence for a vertical tendency. Attention, Perception, \& Psychophysics, 72, 1875-1889.

Durgin, F. H., Pelah, A., Fox, L. F., Lewis, J., Kane, R., \& Walley, K. A. (2005). Self-motion perception during locomotor recalibration: More than meets the eye. Journal of Experimental Psychology. Human Perception and Performance, 31, 398419.

Durgin, F. H., Ruff, A. J., \& Russell, R. (in press). Constant enough: On the kinds of perceptual constancy worth having. In G. Hatfield \& S. Allred (Eds.), Visual experience. Oxford: Oxford University Press.

Foley, J. M., Ribeiro-Filho, N. P., \& da Silva, J. A. (2004). Visual perception of extent and the geometry of visual space. Vision Research, 44, 147-156.

Gibson, J. J., \& Cornsweet, J. (1952). The perceived slant of visual surfaces-optical and geographical. Journal of Experimental Psychology, 44, 11-15.

Gilinsky, A. S. (1951). Perceived size and distance in visual space. Psychological Review, 58, 460-482.

Granrud, C. E. (2009). Development of size constancy in children: A test of the metacognitive theory. Attention, Perception, \& Psychophysics, 71, 644-654.

Hajnal, A., Abdul-Malak, D. T., \& Durgin, F. H. (in press). The perceptual experience of slope by foot and by finger. Journal of Experimental Psychology. Human Perception and Performance. doi:10.1037/a0019950

Harris, C. S. (1963). Adaptation to displaced vision: Visual, motor, or proprioceptive change? Science, 1140, 812-813.

Higashiyama, A. (1992). Anisotropic perception of visual angle: Implications for the horizontal-vertical illusion, overconstancy of size, and the moon illusion. Perception \& Psychophysics, 51, $218-230$. 
Howe, C., \& Purves, D. (2005). Natural-scene geometry predicts the perception of angles and line orientation. Proceedings of the National Academy of Sciences, 102, 1228-1233.

Kammann, R. (1967). Overestimation of vertical distance and slope and its role in the moon illusion. Perception \& Psychophysics, 2, $585-589$.

Kuhl, S. A., Thompson, W. B., \& Creem-Regehr, S. H. (2009). HMD calibration and its effects on distance judgments. ACM Transactions on Applied Perception, 6, 19. doi:10.1145/ 1577755.1577762

Li, Z., \& Durgin, F. H. (2009). Downhill slopes look shallower from the edge. Journal of Vision, 9(11), 6:1-15. doi:10.1167/9.11.6

Li, Z., \& Durgin, F. H. (2010). Perceived slant of binocularly-viewed large-scale surfaces: A common model from explicit and implicit measures. Journal of Vision, 10(14), 13:1-16. doi:10.1167/ 10.14 .13

Li, Z., \& Durgin, F. H. (2011). Design, data and theory regarding a digital hand inclinometer: A portable device for studying slant perception. Behavior Research Methods. doi:10.3758/s13428010-0047-7

Li, Z., Phillips, J., \& Durgin, F. H. (2011). The underestimation of egocentric distance: Evidence from frontal matching tasks. Manuscript submitted for publication.

Loomis, J. M., \& Beall, A. C. (2004). Model-based control of action. In L. M. Vaina, S. A. Beardsley, \& S. K. Rushton (Eds.), Optic flow and beyond (pp. 421-441). Dordrecht, The Netherlands: Kluwer Academic.

Loomis, J. M., da Silva, J. A., Fujita, N., \& Fukusima, S. S. (1992). Visual space perception and visually guided action. Journal of Experimental Psychology. Human Perception and Performance, 18, 906-921.

Loomis, J. M., \& Philbeck, J. W. (1999). Is the anisotropy of perceived 3-D shape invariant across scale? Perception \& Psychophysics, 61, 397-402.

Loomis, J. M., \& Philbeck, J. W. (2008). Measuring spatial perception with spatial updating and action. In R. L. Klatzky, M. Behrmann, \& B. MacWhinney (Eds.), Embodiment, ego-space, and action (pp. 1-43). New York: Taylor \& Francis

Marigold, D. S., \& Patla, A. E. (2006). Gaze fixation patterns for navigating complex terrain. Neuroscience, 144, 302-313.

Matin, L., \& Li, W. (1992). Visually perceived eye level: Changes induced by a pitched-from-vertical 2-line visual field. Journal of Experimental Psychology. Human Perception and Performance, 18, 257-289.

McCready, D. (1986). Moon illusions redescribed. Perception \& Psychophysics, 39, 64-72.

Messing, R. M., \& Durgin, F. H. (2005). Distance perception and the visual horizon in head-mounted displays. ACM Transactions on Applied Perception, 2, 234-250.

Miller, G. A. (1956). The magical number seven, plus or minus two: Some limits on our capacity for processing information. Psychological Review, 63, 81-97.

Murray, S. O., Boyaci, H., \& Kersten, D. (2006). The representation of perceived angular size in human primary visual cortex. Nature Neuroscience, 9, 429-434.
O'Shea, R. P., \& Ross, H. E. (2007). Judgments of visually perceived eye level (VPEL) in outdoor scenes: Effects of slope and height. Perception, 36, 1168-1178.

Ooi, T. L., Wu, B., \& He, Z. J. (2001). Distance determined by the angular declination below the horizon. Nature, 414, 197200.

Philbeck, J. W., Loomis, J. M., \& Beall, A. C. (1997). Visually perceived location is an invariant in the control of action. Perception \& Psychophysics, 59, 601-612.

Proffitt, D. R., Bhalla, M., Gossweiler, R., \& Midgett, J. (1995). Perceiving geographical slant. Psychonomic Bulletin \& Review, 2, 409-428.

R Development Core Team. (2009). R: A language and environment for statistical computing. Vienna, Austria: R Foundation for Statistical Computing. Available at www.R-project.org

Rieser, J. J., Pick, H. L., Ashmead, D. H., \& Garing, A. E. (1995). Calibration of human locomotion and models of perceptualmotor organization. Journal of Experimental Psychology. Human Perception and Performance, 21, 480-497. doi:10.1037/00961523.21.3.480

Ross, H. E. (1974). Behaviour and perception in strange environments. London: Allen \& Unwin.

Ross, H. E. (2010). Perspective effects in frontal slope perception. In A. Bastianelli \& G. Vidoto (Eds.), Fechner Day 2010: Proceedings of the 26th Annual Meeting of the International Society for Psychophysics. Padua, Italy: International Society for Psychophysics.

Sedgwick, H. A. (1983). Environmental-centered representations of spatial layout: Available visual information from texture and perspective. In J. Beck, B. Hope, \& A. Rosenfeld (Eds.), Human and machine vision (pp. 425-458). New York: Academic Press.

Sedgwick, H. A. (1986). Space perception. In K. R. Boff, L. Kaufman, \& J. P. Thomas (Eds.), Handbook of perception and human performance: Sensory processes and perception (pp. 21.221.57). New York: Wiley.

Sedgwick, H. A., \& Levy, S. (1985). Environment-centered and viewer-centered perception of surface orientation. Computer Vision, Graphics, and Image Processing, 31, 248-260. doi:10.1016/S0734-189X(85)80008-6

Shebilske, W. L. (1986). Baseball batters support an ecological efference mediation theory of natural event perception. Acta Psychologica, 63, 117-131.

Volcic, R., Kappers, A. M. L., \& Koenderink, J. J. (2007). Haptic parallelity perception on the frontoparallel plane: The involvement of reference frames. Perception \& Psychophysics, 69, 276 286.

Wallach, H., \& O'Leary, A. (1982). Slope of regard as a distance cue. Perception \& Psychophysics, 31, 145-148.

Wand, M., \& Ripley, B. (2009). KernSmooth: Functions for kernel smoothing for Wand \& Jones (1995). R package version 2.23-3. Available at http://cran.r-project.org/web/packages/KernSmooth/ index.html

Wu, B., Ooi, T. L., \& He, Z. J. (2004). Perceiving distance accurately by a directional process of integrating ground information. Nature, 428, 73-77. 